\title{
Time, space, and the wireless community network
}

\author{
Marco Adria \\ Director of the Graduate Program in Communications and Technology \\ University of Alberta \\ $\leq$ marco.adria@ualberta.ca $>$
}

\begin{abstract}
Wireless zones are of increasing interest to scholars and practitioners of community informatics because of their promise of universal access to technology. They have been established quickly by municipalities, cooperatives, and private companies, especially in urban centres. The spatial organization of wireless zones conforms to the design of urban spaces and to existing or envisioned transportation routes. Following transportation routes for the design of communication infrastructure has its roots in the $19^{\text {th }}$ century strategy of threading the telegraph network through the continental railways. The implications of such a strategy for community uses of technology are considered in this article. Drawing on medium theory, it is argued that participation in community informatics in an era of virtual identities and mediated communication requires attention to the broad effects of technology, particularly in connection to changing conceptions of time and space. An important implication for community networks is that a preferred design option for the network may be to establish clusters of wireless islands that are characterized by the use of both mediated and non-mediated communication and by place-based wireless content.
\end{abstract}

The reduction of distances has become a strategic reality bearing incalculable economic and political consequences, since it corresponds to the negation of space (Virilio 2007, 149).

\section{Introduction}

Wireless zones have been established by municipalities, cooperatives, and private companies, especially in urban centres, but also in small rural communities (Vulcan 2004). These zones are of interest to those studying and organizing community networks because they seem to resolve or address the problem of providing universal access to members of a community. A wireless zone may be located either indoors or outdoors, with access to users provided through devices such as laptop computers or personal digital assistants. The spatial organization of wireless zones can be considered in relation to the historical design of urban spaces and of transportation routes. In the $19^{\text {th }}$-century, the business strategy was adopted of threading the telegraph network through the continental railways. The implications of a similar strategy for community uses of technology are considered in this article. Drawing on medium theory, I argue that in an era of virtual identities and mediated communication, participation in community informatics requires attention to the broad effects of technology. Conceptions of time and space are reconfigured by wireless zones. Some implications of this change for community networks are offered. 
Municipal wireless zones have been established in large U.S. cities such as Philadelphia and San Francisco and in some Canadian cities including St. John, New Brunswick, and Edmonton, Alberta. The extent to which these zones are free (that is, allowing people to use the system without financial charge), ubiquitous (covering a large geographical area), and open (without limits on the content available to users) varies considerably. Wireless Philadelphia was an early adopter, establishing a wireless zone in 2004 that now covers a large part of the landmass of the city, some 10 square miles (Proof of concept acceptance 2007). The project includes an initiative to provide subsidized access to high-speed Internet for low-income citizens. The project has not proceeded as quickly as planned, after the private provider, Earthlink, found that the cost of hardware was higher than anticipated (Snags 2007).

In Edmonton, a wireless zone has been established in core areas of the downtown (Edmonton 2007), with free access provided in spaces in and around City Hall. Plans for extending the network would result in forming a northeast axis of approximately 10 kilometres, beginning at the University of Alberta's main campus south of the North Saskatchewan River, following the light-rail transit (LRT) trains across the river, through the downtown core of the city, and to the LRT's northern terminus in suburban Belvedere. Beyond metropolitan Edmonton, a wireless zone has been contemplated as one of the amenities associated with the construction of a fast-train corridor between Alberta's two major cities. The Edmonton-Calgary corridor wireless zone would also form an axis, but over a much greater distance. A 300-kilometre wireless corridor would be formed north to south, tracing the major highway connection between the two cities and also tracing the route of the proposed fast train.

\section{Wireless zones and medium theory}

To set wireless zones for community development in its domain of inquiry, we should note that the theoretical basis for community informatics remains relatively underdeveloped (Stoecker 2005; De Moor \& Weigand 2006). It has remained rooted in an ethos of praxis, with practitioners and scholars concerned mainly with explaining the values by which the social movement may be sustained (Buré 2006; Schuler \& Day 2004). Medium theory provides a possible theoretical basis for community informatics because it is concerned with identifying imbalances and contradictions in human perception following from historical media innovations. It also provides a relevant critical perspective, since it argues for a broadly-based social ecology of media. It allows for systematic analysis of the embeddedness of technology use in social groups, which is integral to the practice of community informatics.

The French medium theorist Paul Virilio (2006) sees technology as the most profound of influences on human perception. He regards media innovation as invoking the same effects on perception as that of the larger category of technology. An elision of media into the broader category of technology follows the practice of medium theorists such as Innis (1951), Marshall McLuhan (1964), and, more recently, Joshua Meyrowitz (1985) and Ronald Deibert (1997). Medium theorists argue that new technologies create new social and psychological environments, in which large-scale changes in patterns of behaviour may be discerned. Changes in the patterns of social action described by medium theory are not directly caused by technology but are more likely to become potent in the new environment. A new medium favours some changes and discourages others. For example, the almost universal use of television has served to increase the permeability of divisions in the stages of child development, since through television children now witness (previously private) adult conversations (Meyrowitz 1985). Establishing a primetime viewing period in the evening reduced, but did not eliminate, differences in what was once viewed as properly belonging to childhood and what is now considered to be associated with adulthood. 
Deibert (1997) points out that the bias or favouring aspects of a technology do not appear spontaneously as individuals and groups abruptly drop certain social preferences and adopt others. Instead, a 'web of social preferences' changes over time. The changes in question are therefore inter-generational changes, not intra-psychic ones. Social preferences are relatively intractable in the short term. Furthermore, over longer periods of time, technologies that are used intensively may 'reverse' their effects, in one historical era helping to create a shared sense of identity and a shared purpose, but in another era encouraging atomism and anomie (McLuhan \& McLuhan 1988).

Community informatics theorists and medium theorists are not concerned with mutually exclusive theoretical concerns. For example, scholars of community informatics try to address the unintended consequences of technology adoption and therefore have in part adopted the lens of medium theory. Medium theory's central insight is that social and economic blind spots are created by new technologies. These blind spots may aggregate to form a regime or a 'bias' of either space or time (Innis 1951). A society's dominant technology represents an orientation to or emphasis on one of the human senses, which then becomes associated with a widely held bias of space or time. Writing, with its emphasis on the visual sense, is associated with a bias of space, and this bias has been intensified by the proliferation of the screen display. With the invention of writing, information could be delivered over vast territories, favouring the rise of empires. McLuhan referred to this historical shift in his epigram, "an eye for an ear" (McLuhan 1964). The oral culture and social environment were left behind, although not entirely, since orality constitutes much of the content of the new medium.

For those seeking to understand and respond fully to the implications of technological innovation, there is work to be done in identifying the blind spots associated with the design, adoption, and use of the new technology. Like community network scholars and practitioners, medium theorists seek to assess a new technology in its social context by comparing local cultural changes with the pattern of changes observed in previous historical eras. The advent of wireless zones which herald some uses of technology will be widely recognized and acknowledged. Others will remain invisible.

Medium theory, while seeking to assess and describe, does not eliminate human agency from new social environments. Change is possible, but often in incremental terms and in circumscribed contexts. Jacques Ellul (1981) states the following in a way that would provide a roughly representative statement for other prominent medium theorists:

[I]t was never my goal to go back, to declare that technology must be eliminated. I was looking for a new direction. ... All this led me to concentrate on local initiatives, that is, to rely on direct and close relationships to form groups for investigating the issues that require people to take a stand on technology and the technological system, but which are also very concrete (80-81).

The use of the Internet for mediating local activities corresponds to either of two basic models described by Feenberg and Bakardjieva (2004). These are the 'consumption' and 'community' models. The consumption model involves searching for and retrieving information, which is made available for a market price. In the consumption model, users rarely talk to one another, because price is the medium of communication:

Privacy, anonymity, reliability, speed, and visual appeal are desired properties of this virtual space, mobilizing armies of designers in search of competitive technical solutions (1). 
By contrast, the community model represents 'relatively stable, long-term online group associations mediated by the Internet' (2). These associations are largely uneconomic, providing returns that are connected to the community's values, norms, and meanings (Etzioni \& Etzioni 1999). The community informatics ideal is based on the community model of Internet use described by Feenberg and Bakardjieva. It seeks what Kellner calls more ludic uses of technology, that is, the more playful kinds of uses representing a 'more ecological mode of social organization' (Kellner 1998, 14). Such an ecology is decentralized, immersed in humanistic concerns, and responsive to direct human observation and concrete social action.

Yet the consumption and community models of the Internet described by Feenberg and Bakardjieva are themselves a set of recently developed conceptual alternatives to the more historically stable model of military logistics described by Virilio (2006). This is the model that gave life to the Internet and which is still used to inform certain aspects of the consumption model. Two fundamental aspects of the Internet as a social environment will be discussed: changing conceptions of time and of social space, including altered patterns in the movement of people in urban areas. Some implications of these changes are then suggested for communities seeking to use wireless zones within the praxis of community informatics.

\section{Changing conceptions of time implied by the wireless zone}

Media innovations are associated with changes in how people conceive of time. As noted, Innis has drawn attention to the biases of either time or space that have been introduced by the widespread adoption of a new medium. Radio in North America in the 1930s and 1940s, for example, was associated with an increasing centralization of administrative power (Innis 1951).

Considering the influence of the Internet on conceptions of time, we should observe that the communication environment of the Internet is 'always on.' This implies new patterns of interaction for individuals and groups. Time is continuous and unpunctuated by interventions by individuals or groups. To take a familiar example, online discussions continue without discernible beginnings or ends. Mass popular culture, which is propagated by the Internet and forms the main point of interest for millions of users, takes the form of a 'flow,' largely unpunctuated by clock or calendar. Similarly, the Internet's influence on communication was presaged by the social effects of the telegraph (Lubrano 1997; Standage 1998). Following the practices introduced by the telegraph, the Internet is oriented to a market of prices. With the advent of the telegraph, the practice of arbitrage, that is, of buying cheaply in one location to sell dearly in another, was reduced in importance (Carey 2003). The telegraph introduced what were to become elaborated practices of buying and selling in time rather than in space. Such practices as futures, options, and hedging followed. The Internet has extended the exchange of information and prices throughout the day and night without pause.

For scholars and practitioners of community informatics, continuous time in a market of prices means that the bracketing of social life with concrete action has become, as it were, an anachronism. Action is seen as continuous in time, without any advantage accruing to individuals and groups choosing to live and work in proximity to one another, rather than in a virtual relationship. Decisions, too, are now part of a seamless rolling forward in time.

Historical examples of the development of technologies can illustrate this interpretation of technology. Consider the Missile Crisis of 1962 (Adria 2003). On October 22 of that year, in response to a perceived buildup of Soviet weapons in Cuba, President Kennedy requested that Canadian defence forces adopt a state of heightened readiness. On October 24, Kennedy demanded that Cuba remove its missiles and imposed a blockade. At 
about 1 p.m. that day, the Canadian units of NORAD assumed, 42 hours after being asked to do so, the state of readiness requested by the U.S. The delay became a source of bitter political criticism and the eventual defeat of the Diefenbaker government at the polls the following year. The Soviet missiles had been moved to a location close enough to the U.S. that the time-frame for decisions to act had been condensed to an unacceptable degree. Virilio notes that, 10 years later,

in 1972, when the normal waiting time was down to several minutes - ten for ballistic missiles, a mere two for satellite weapons - Nixon and Brezhnev signed the first strategic arms limitation agreement in Moscow. ... [T] his agreement . . . threatens from one day to the next to reduce the warning time for nuclear war to less than one fatal minute - thus finally abolishing the Head of State's power of reflection and decision in favor of a pure and simple automation of defense systems (Virilio 2006, 155; italics in the original).

There is no claim being made here that the Internet, or any technology, necessarily or directly causes one decision or another to be taken in either world politics or community networks. However, communities should remain sensitive to the direction of changes in patterns of behaviour favoured by the Internet, in the manner described by Deibert (1997) in his study of the structuring effects of the printing press. The conversation, the small group discussion, and the congress are displaced by the Internet to be supplanted by interactions between individuals and groups separated in space. Like the cellphone, the wireless zone 'thickens' time because it allows people to do more than one thing at once, at the expense of spontaneous expression and a wider expanse of authentic human relationships (Fortunati 2002).

\section{Changing conceptions of space and the wireless community network}

With the telegraph and then the Internet, fundamental changes in how time is conceived have been accompanied by shifts in how space is regarded and used. Just as time is 'thickening' as wireless zones are established, space will continue to be 'filled up' with programmed activities that are recorded, tracked, and archived by surveillance technologies. To understand modern organization, states Nigel Thrift, we must understand the capacity to 'register, understand, and engineer smaller spaces and times' $(2001,2)$. The wireless zone is an engineered smaller space in which an intensified monitoring of human activity is made possible at all times.

A useful comparison of the community network and the Internet may be made to reveal something of changes in the uses of space by considering the intention of individuals and groups in the respective creation of each. The community network arose out of the intention to create meaningful spaces within which democratic processes could be renewed. The originating intention of the Internet, by contrast, was to protect and isolate space as a strategy of consolidating national security. The network's purpose would be to decentralize information and communication capacities to reduce the effects of nuclear strikes on U.S. soil. Commenting on the consequences for space introduced by the telegraph and then the Internet, Virilio states that

[t] he countryside, the earth is henceforth give over, definitively consecrated to war by the cosmopolitan mass of workers, an army of laborers speaking every language, the Babel of logistics (2006, 85).

Virilio points out that the Internet has not changed as a technological form since its inception. Its design continues to rely on speed, simultaneity, and vectors as organizing principles. The speed of communication has been increased to the level of simultaneity, with 
applications allowing for real-time interaction, including videoconferencing, instant messaging, and Internet phones. The vector is concerned with accurately predicting locations, trajectories, and destinations. With the release of Google Map, Earth, and Street, the vector fully constitutes the design of the urban infrastructure and gives form to the wireless zone.

The wireless zone encourages certain patterns of movement for individuals and groups in space, which are moderated and managed by the city's architecture. The architecture of the city is revealed in the design of the built environment and includes buildings and homes, but also bridges, streets, airports, utility rights of way, open fields of vegetation or rubble, security checkpoints, and bodies of water. The Internet conforms to the architecture of the city and to its main function, which is to ensure that the movement of people is more or less predictable and at all times subject to direct control. For example, the prolonged occupation of the streets by large groups has historically been suppressed since it has been regarded as an incitement to violence. The vast surface of the urban street is to remain a vehicle throughway in constant motion. Even insubstantial resistance to this principle, in the form of slow driving, has given rise to the new mental maladjustment of 'road rage.'

Similarly, the presence of the fraction of the population who migrate from one place to another is a permanent feature of the city - a cohort that the community informatics ideal seeks to serve and support. The design of the city provides for the continuous movement of migrants through zoning regulations which give progressive economic advantage according to the relative permanence of homes. The homeless inhabitants of the city, too - those who are on their way to nowhere in particular - are maintained in circulation within the city. This is accomplished through enforcing ordinances against loitering, but also through enacting parking bylaws which do not allow any part of the roadway to remain covered with a vehicle or anything else for more than a day or two.

The infrastructure for wireless zones are physically entwined with this movementmanaging infrastructure of the city. The equipment for Wireless Philadelphia includes towers owned by the private company Earthlink, and licenced by the Philadelphia City Department of Licences and Inspections. Routers are located on light standards at a density of 30 per square mile and licenced by the Department of Streets (Proof of concept acceptance 2007). The intertwining of community networks, technology, and the urban infrastructure is reflected most clearly in the ownership and management of the base network by incumbent telecommunication companies.

\section{Design alternatives for wireless community networks}

The community network could take into account changes in conceptions of time in several ways. It might create opportunities for face-to-face gatherings in which people meet one another for impromptu purposes and allow for chance encounters with strangers. Similarly, it might ensure that summaries of asynchronous conversations are provided in different modes; the outcome of an asynchronous discussion that has unfolded over several months, for instance, could be presented orally. By understanding changes in conceptions of time, and responding to these changes deliberately and concretely, community networks would be in a better position to make meaningful use of new wireless zones.

Likewise, community informatics as a social movement and as an ideal is constituted by individuals and groups whose ethos for establishing a network is that they are not moving. Instead, they contribute to the development of a meaningful place, which is part of the identity of the community. If the city is constantly on the move in the ways described, the community network's use of wireless zones might be designed to alleviate or at least take account of architectural elements that would undermine the community network's vitality. 
One method that might be used to strengthen the connection of the community network as wireless zones are established would be to reject or modify the strategy of full virtualization. Attention might be given to siting the physical space of the community network in historically or symbolically significant locations. This would underline the community network's commitment to a particular space. In this way, the 'community' model of the Internet described by Feenberg and Bakardjieva could be confirmed. In response to the increasingly opaque office towers in cities, visibility could be provided to the interior of the community network's premises from the street at all times of the day. Regular congregation within the space could be organized for such community-building activities as social rituals of various kinds, regular and spontaneous celebrations, and meetings for administration and governance.

Encouraging the flexible and morphological use of space in the community is a possible means of complementing or resisting the implications for space that are extended by the wireless zone. Community networks using wireless zones as a key part of their strategies may wish to create forms of interaction and organization that are alternative to those characterizing the logistics and tactics of programmed space. McLuhan noted that with the introduction of the television into the home, the circle of the family had been disturbed and had now become a semi-circle (McLuhan \& Szklarek, 1999). The use of metaphorical and material circles has informed First Nations culture and practices and could be considered by the community network as a potentially useful design principle.

Finally, the Urban Tapestries project in West London is a prototype for producing locally developed cultural work as the core of a community wireless zone (Urban Tapestries Project 2007). Here, a public authoring system was used to demonstrate the creative and socially progressive activities that are possible in a wireless zone. Communities posted their impressions of the sounds and sights of city spaces. Neighbourhoods explored new ways to learn about local history and contemporary issues. Using relatively inexpensive and easily obtained components, 'feral robots' were even commissioned to record local levels of air pollution in communities, for subsequent analysis.

The ubiquitous cosmopolitan blanket of wireless access may not be desirable for community networks. Instead, a cluster of wireless islands may be preferable. Within each wireless island, the design principles could emphasize the strategic combination of physical and virtual space, network and face-to-face interaction, and small group transactions and convening the congress.

\section{Wireless community networks in time and space}

A totalizing view of technology is evident in the work of Virilio, as it is in the work of Martin Heidegger, Jacques Ellul, and Marshall McLuhan. From this perspective, technology is seen as a demiurge, that is, as ultimately influencing and shaping all human experience. Such a view underestimates the diversity of technological forms, the varying intentions of users, and the resiliency of human agency. The method employed by these theorists, however, is to uncover the unrecognized structuring influences of technology as a means of understanding its full scope in human life. Achieving such an understanding need not be grounded in an anti-technological stance, but may be rooted in the conviction that without understanding of what is at stake in technological change, meaningful social action in response is impossible. If the gestalt of medium theory could be stated in a word, it might well be to understand. Medium theory provides a route to insight and rich description, from which strategies for action may be devised.

Community informatics as an area of study and praxis has developed through several eras of technological development already. The wireless zone represents yet another stage in 
this progression. By grounding its practical and strategic work in the fundamental categories of time, space, and the movement of people, and by fully employing the explanatory power of medium theory, community informatics could anticipate a sound basis for further development. The approach may also suggest practical methods for understanding and responding to the social consequences, intended and unintended, of the wireless zone.

\section{References}

Adria, M. (2003). Arms to communications: Idealist and pragmatist strains of Canadian thought on technology and nationalism. Canadian Journal of Communication 28, 167-84.

Buré, C. (2006). Digital inclusion without social inclusion: The consumption of information and communication technologies (ICTs) within homeless subculture in Scotland. Journal of Community Informatics 2(2).

Carey, J. (2003). Time, space, and the telegraph. In Communication in history: Technology, culture, society, Crowley, D., \& Heyer, P., eds., 157-65. Toronto: Pearson.

De Moor, A., \& Weigand, H. (2006). Effective communication in virtual adversarial collaborative communities. Journal of Community Informatics 2(2).

Deibert, R. (1997). Parchment, printing, and hypermedia: Communication in world order transformation. New York: Columbia University Press.

Edmonton introduces free public wireless Internet access. (2007, June 26). Retrieved June 26, 2007 from http://www.edmonton.ca/citygov/newsrls/rls0418.pdf. Accessed on 26 June 2007.

Ellul, J. (1981). W. Vanderburg, ed. J. Neugroschel, tr. Perspectives on our age: Jacques Ellul speaks on his life and work. New York: Seabury.

Etzioni, A., and Etzioni, O. (1999). Face-to-face and computer-mediated communities: A comparative analysis. The Information Society, 15, 241-48.

Feenberg, A., \& Bakardjieva, M. (2004). Community in the digital age: Philosophy and practice. In Feenberg, A., \& Barney, D., eds., 1-28. Lanham, Maryland: Rowman \& Littlefield.

Fortunati, L. (2002). The mobile phone: Towards new categories and social relations. Information, communication \& society 5(4), 513-29.

Innis, H. (1951). The bias of communication. Toronto: University of Toronto Press.

Kellner, D. (1998). Virilio, war, and technology: Some critical reflections. Illuminations. Retrieved June, 13, 2007 from http://www.uta.edu/huma/illuninations/kell29.htm.

Lubrano, A. (1997). The telegraph: How technology innovation caused social change. New York, USA: Garland Publishing, Inc.

McLuhan, M. \& McLuhan, E. (1988). The laws of media: The new science. Toronto: University of Toronto Press.

McLuhan, E., \& Szklarek, J., eds. (1999). The medium and the light: Reflections on religion. Toronto: Stoddart.

McLuhan, M. (1964). Understanding media: The extensions of man. New York: New American Library.

Meyrowitz, J. (1985). No sense of place: The impact of electronic media on social behavior. New York: Oxford University Press. 
Newman, P. (1973). Renegade in power: The Diefenbaker years. Toronto: McClelland and Stewart.

Proof of concept acceptance: Overview. (2004). Retrieved June 26, 2007 from http://www.wirelessphiladelphia.org/blog_detail.cfm/blog/19.

Schuler, D., and Day, P. eds. (2004). Shaping the network society: The new role of civil society in cyberspace. Cambridge, MA: MIT Press.

Snags, delays plague Philadelphia WiFi network. (2007). Retrieved November 26, 2007 from http://www.ecommercetimes.com/rsstory/60382.html

Standage, T. (1998). The Victorian Internet: The remarkable story of the telegraph and the nineteenth century's on-line pioneers. New York: Walker.

Stoecker, R. (2005). Is Community Informatics good for communities? Questions confronting an emerging field. Journal of Community Informatics 1(3).

Thrift, N. (2001). Timing and spacing. Paper presented to 'Spacing and timing: Rethinking globalization and standardization. Palermo, Italy, 1-3 November.

Urban tapestries project. (2007). Retrieved June 27, 2007 from http://urbantapestries.net.

Virilio, P. (2006). Speed and politics. M. Polizzotti, tr. Los Angeles: Semiotext(e) . (1997). Open sky. J. Rose, tr. London: Verso.

Vulcan gets connected to wireless. (2004). Retrieved November 26, 2007 from http://cgi.bowesonline.com/pedro.php?id=71\&x=story\&xid=117087 